\title{
Research on children's air purifier based on Emotional design
}

\author{
Jiawei Liu ${ }^{1}$, Dongming $\mathrm{Ma}^{2}$ and Hao Qian ${ }^{1 *}$ \\ ${ }^{1}$ Departments of Mechanical and Electrical Engineering, University of Beijing University of Chemical Technology, 100029, china \\ ${ }^{2}$ Departments of Mechanical and Electrical Engineering, University of Beijing University of Chemical Technology, 100029, china
}

\begin{abstract}
The purpose of this article is to explore new functions and experience methods for children's air purifiers based on the theory of emotional design. The research method is, first, to collect perceptual vocabulary and typical samples, and use the semantic difference method to build a perceptual evaluation table. Secondly, the analysis data is imported into SPSS software for factor analysis and principal component analysis. Establish user demand models for children's air purifiers through user interviews. Finally, using the hierarchical analysis method to get the three elements of design: shape, function, experience, and then use the three elements of design to guide practice. The significance of the research lies in the use of emotional design methods, which provide new solutions for communication between parents, children and purifiers.
\end{abstract}

\section{Introduction}

Children are in the stage of all-round growth of psychological and physiological functions. The immature respiratory system makes children vulnerable to the threat of air pollution. Children who are indoors for a long time and exposed to formaldehyde, second-hand smoke, volatile organic pollutants, particulate matter, etc. in the home indoors can easily cause acute respiratory infections[1]. Therefore, children's air purifiers are of great significance to protect children's physical health and safety, but there are fewer types of air purifiers designed for children on the market. In addition, children as a special group must fully consider their behavior characteristics and emotions when designing products for them. factor.

\section{Emotional design of children's air purifier}

\subsection{Development Status of Children's Air Purifiers}

With the increasing environmental pollution in China's urbanization process, people's requirements for air quality have become higher and higher, and the pursuit of a healthy living quality has brought a broad market for the design and development of air purifiers[2]. The country's vigorous development of industrial design has driven the rapid innovation and rapid development of China's children's products industry. In addition, the country has actively encouraged the implementation of the "second child" policy, which has increased market share and demand[3]. At present, most of the children's purifiers on the market only focus on the innovation of appearance and technology. They do not pay attention to the interactive experience and emotional communication between parents and children.

\subsection{Emotional Design}

Emotion is an attitude that meets the subject's selection needs, and it is affected by values, culture, spirit, and background. Donald Norman divides human emotion level into three levels, instinct level, behavior level and reflection level[4]. The instinctive layer refers to the user's intuitive feelings about the product's appearance, including material elements such as shape, color, texture, etc ; the behavior layer refers to the user triggering emotions in the use of the product, focusing on the usability and convenience of the user's use of the product; The reflection layer refers to seeking the user's memory and experience pinned on the product, focusing on the symbolic meaning and social value of the product, reflecting the user's value orientation and aesthetic characteristics, and is the highest level of emotional design[5].

\subsection{Emotional design process for children's air purifiers}

Using the perceptual engineering method, the children's emotional intentions are related to the design elements of the air purifier, and the perceptual intentions are quantified and transformed into design elements, so as to design another child's air purifier that is satisfactory to consumers[6]. The research ideas of children's air purifiers are as follows: (1) Collection of perceptual vocabulary for children's air purifiers, selection of typical children's air purifier samples, analysis using SD method to form a

*Corresponding author's e-mail: 842906190@qq.com 
perceptual evaluation form; (2) importing intention evaluation values into SPSS software, Perform factor analysis and principal component analysis; (3) Design interview content based on the extracted principal components and emotions at three levels, and conduct target user interviews. (4) The function list and user demand model are obtained based on the interview results. (5) Use the hierarchy analysis method to draw the three elements of the design and guide the design examples. The research process is shown in Figure 1.

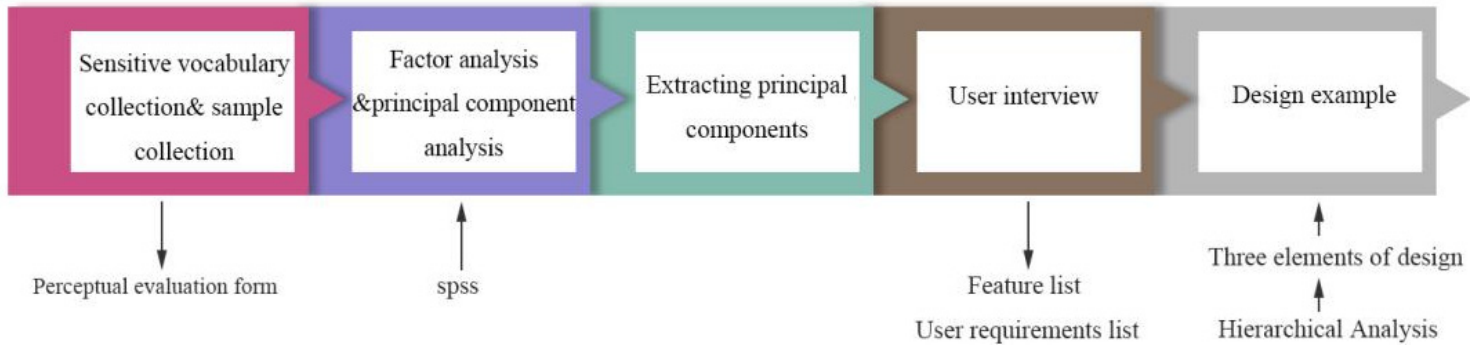

Figure 1. Research Process

\section{Analytical methods for children's air purifiers}

Based on the perceptual vocabulary and typical samples, the SD method is used to establish the perceptual evaluation form to analyze the emotional needs of target users, which is conducive to extracting the emotional design elements of the product.

\subsection{Collection and Screening of Children's Air Purifiers' Perceptual Image Words}

Through online and offline literature searches, 302 perceptual words were initially collected. Secondly, card classification was performed on 302 sentimental words. Using KJ method and expert evaluation, 32 sentimental words were obtained. The evaluation results were screened and ranked. Finally, the 9 sentimental words with the highest selection rate were determined, and the antonyms of each sentimental word were selected. The perceptual image phrases are shown in Table 1.

Tab.1. Filtered intent phrases

\begin{tabular}{cccccc}
\hline Numbering & 1 & 2 & 3 & 4 & 5 \\
\hline Intent words & rounded & Simple & Lovely & safe & Smart \\
\hline
\end{tabular}

\subsection{Collection of typical samples of children's air purifiers}

By consulting the literature and browsing the website, some well-known air purifier brands were collected, and children's air purifiers were selected from each brand as the research sample of this thesis. These brands include three dads, COWAY, AO. Smith, German Hanlang, Xiaomi, Panasonic, etc. initially screened 23 samples. After expert evaluation and card classification, grouping and categorizing according to the shape of the product, 8 typical samples of children's air purifiers were finally obtained, as shown in Table 2.

Table 2. Representative children's air purifier samples

\begin{tabular}{|c|c|c|c|c|}
\hline Icon & $\begin{array}{l}\text { P } \\
\text { (P. } \\
\end{array}$ & & 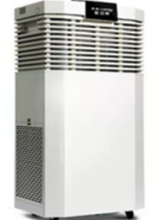 & -1 \\
\hline Sample number & Sample 1 & Sample2 & Sample 3 & Sample 4 \\
\hline Icon & & & & \\
\hline Sample number & Sample 5 & Sample 6 & Sample 7 & Sample 8 \\
\hline
\end{tabular}




\subsection{Sample evaluation and analysis}

A total of 106 families were selected, and each family included parents and children. According to the product's form, usage method and purification efficiency, each group of families was given a semantic vocabulary score on 8 representative samples through subjective feelings, so as to construct a perceptual evaluation form. Guided by the semantic meaning measurement method, the evaluation dimension is divided into 7 levels, and the corresponding scores are $-3,-2,-1,0,1,2$, and 3 , of which -3 is the target group's vocabulary for the sample. Totally dissatisfied, 3 said very satisfied. In this study, 102 questionnaires were distributed through questionnaires, of which 100 were valid. With the help of the questionnaire star assessment tool, the perceptual evaluation values after screening were sorted out, and the mean value matrix table was obtained, as shown in Table 3.

Table3. Mean of evaluation of representative samples

\begin{tabular}{cccccc}
\hline \multirow{2}{*}{$\begin{array}{c}\text { Sample } \\
\text { number }\end{array}$} & Round-sharp & $\begin{array}{c}\text { Simple- } \\
\text { complex }\end{array}$ & $\begin{array}{c}\text { Lovely- } \\
\text { mature }\end{array}$ & Safety-danger & $\begin{array}{c}\text { Smart- } \\
\text { Traditional }\end{array}$ \\
\cline { 2 - 6 } & -1.013 & 1.215 & -0.815 & 1.513 & 1.268 \\
\hline 1 & 0.115 & -1.725 & 0.015 & -1.328 & -2.015 \\
\hline 2 & 0.216 & -0.676 & 0.632 & -1.913 & -1.343 \\
\hline 3 & 1.820 & 1.613 & 1.067 & 1.603 & 2.033 \\
\hline 4 & 2.145 & 1.138 & 2.689 & 1.078 & 1.576 \\
\hline 5 & 1.136 & -1.049 & 1.003 & -1.001 & -1.203 \\
\hline 6 & -1.117 & -1.003 & -2.375 & -0.315 & -2.035 \\
\hline 7 & 2.020 & 1.066 & 1.732 & 1.647 & 0.379 \\
\hline 8 & & & & &
\end{tabular}

\section{Extraction of principal components}

The complexity of the internal variable data increases the difficulty of cognition. Therefore, by exploring the correlation of the variables, the dimensionality reduction of the perceptual image factors is performed[7]. The statistical software SPSS was used to reduce the dimensionality of the matrix table, so that the semantic meaning of perceptual vocabulary can be concentrated, which is conducive to the accurate extraction of children's air purifier design forms.

\subsection{Factor analysis test}

KMO and Bartlett sphericity tests were used to determine the suitability of factor analysis. As can be seen from Table4 below, the Bartley spheric test statistic is 132.862 , which is a large value with a significance of 0.000 . This value can determine that the correlation coefficient matrix is significantly different from the identity matrix. In addition, it is suitable according to the KMO metrics 0.70.8 given by Kaiser, and the KMO value of 0.746 is in line with the scope of factor analysis.

Table4. KMO and Bartlett's Test

\begin{tabular}{|c|c|c|}
\hline \multicolumn{3}{|c|}{ KMO and Bartlett's Test } \\
\hline \multicolumn{2}{|c|}{ KMO Sampling suitability } & 0.746 \\
\hline \multirow{3}{*}{ Bartlett sphericity test } & Approximate chi-square & 132.862 \\
\hline & Degrees of freedom & 10 \\
\hline & Saliency & 0.000 \\
\hline
\end{tabular}

\subsection{Factor extraction}

are greatly affected by two factors of children's air purifiers, and can be analyzed in the next step.
Principal component analysis is used to set the initial eigenvalue less than 1 and no consideration is given. It can be seen from Table 6 that the cumulative interpretation variance of the first main factor is $70.181 \%$, and the cumulative interpretation variance of the second main factor is $95.671 \%$. After extracting and rotating, its cumulative contribution rate is $95.671 \%$, which is higher than the standard of $80 \%$. The above data shows that users 
Table5. Principal component extraction

\begin{tabular}{c|ccc|ccc|ccc}
\hline \multirow{2}{*}{$\begin{array}{c}\text { Ing } \\
\text { redi } \\
\text { ent }\end{array}$} & Total & $\begin{array}{c}\text { Variance } \\
\text { percentag } \\
\mathrm{e}\end{array}$ & $\begin{array}{c}\text { Accumul } \\
\text { ation } \%\end{array}$ & \begin{tabular}{c} 
Total \\
\cline { 2 - 8 }
\end{tabular} & $\begin{array}{c}\text { Variance } \\
\text { percentag } \\
\mathrm{e}\end{array}$ & $\begin{array}{c}\text { Accumu } \\
\text { lation } \%\end{array}$ & $\begin{array}{c}\text { Total } \\
\text { percentag } \\
\mathrm{e}\end{array}$ & $\begin{array}{c}\text { Accumu } \\
\text { lation } \%\end{array}$ \\
\hline 1 & 3.509 & 70.181 & 70.181 & 3.509 & 70.181 & 70.181 & 2.762 & 55.246 & 55.246 \\
\hline 2 & 1.274 & 25.489 & 95.671 & 1.274 & 25.489 & 95.671 & 2.021 & 40.425 & 95.671 \\
\hline \multicolumn{8}{c|}{ Extraction method: principal component analysis. } \\
\hline
\end{tabular}

In order to further explore the correlation between perceptual words and principal components, the maximum variance method of principal component analysis was used to obtain the rotated component matrix, as shown in Table 6.

The larger the absolute value, the greater the correlation between the image word and the principal component. The correlation between the principal component 1 and "safety", "easy to use", and "intelligent" is relatively large. These three adjectives can be called the user's experience in using the purifier. Principal component 2 has a large correlation with "roundness" and "cuteness". These two adjectives can be said to be the intuitive feeling when users see a child's air purifier. After consulting the relevant literature, the principal component 1 is called the usability factor, so the principal component 2 is called the sensory factor.

Table6. Principal component extraction

\begin{tabular}{ccc}
\hline \multirow{2}{*}{ Perceptual vocabulary } & \multicolumn{2}{c}{ Ingredient } \\
\cline { 2 - 3 } & 1 & 2 \\
\hline Round & 0.239 & 0.947 \\
\hline Simple & 0.954 & 0.255 \\
\hline Lovely & 0.189 & 0.967 \\
\hline Safety & 0.960 & 0.096 \\
\hline Smart & 0.915 & 0.338 \\
\hline
\end{tabular}

Extraction method: principal component analysis.

Rotation method: Caesar's normalized maximum variance method.

a. The rotation has converged after 3 iterations.

\section{Child Air Purifier User Experience Interview}

According to the sensory factors and usability factors obtained from the principal component analysis method, starting from the sensory and usability aspects of the product itself, an interview questionnaire was designed to conduct a deeper demand analysis. Combined with the interview data results, the final user demand model is constructed.

\subsection{Interviewee}

A total of 30 test subjects were collected for this interview, including 3 experts and professors and 27 families.

Considering that children's parents are the decision makers of children's air purifier consumption, the product form should be considered in the psychological cognition and consumption level of this parent's age[8], so we selected interview subjects based on the family. Professionals: experts in perceptual engineering research, talents in product design; family: children 6-13 years old and their parents.

\subsection{Interview Content}

The interview content was designed based on the principal component factors affecting the design elements of children's air purifiers.

1. What kind of purifier do you like, description of shape, color, material and size?

2. Opinions on the functions of existing air purifiers, or what new functions do you want to add.

3. What kind of spiritual experience can children's air purifiers bring?

\subsection{Interview data collation}

The interview data of 30 testers were analyzed. Based on the method of perceptual engineering, combined with the results of factor analysis of samples and perceptual vocabulary, the emotional needs of target user children were quantified, and a user demand model was constructed, as shown in Figure 2. 


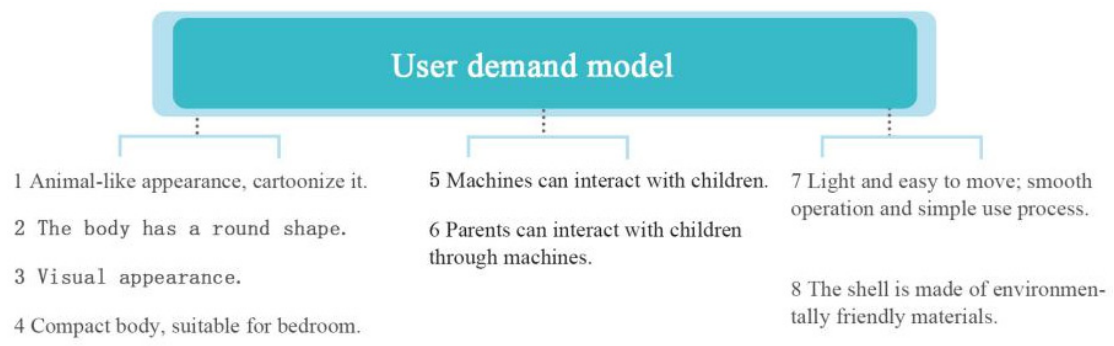

Figure 2. User demand model

\section{Extraction of design elements for children's air purifiers}

Integrate the results of factor analysis and user demand models, integrate content and data, and use the qualitative

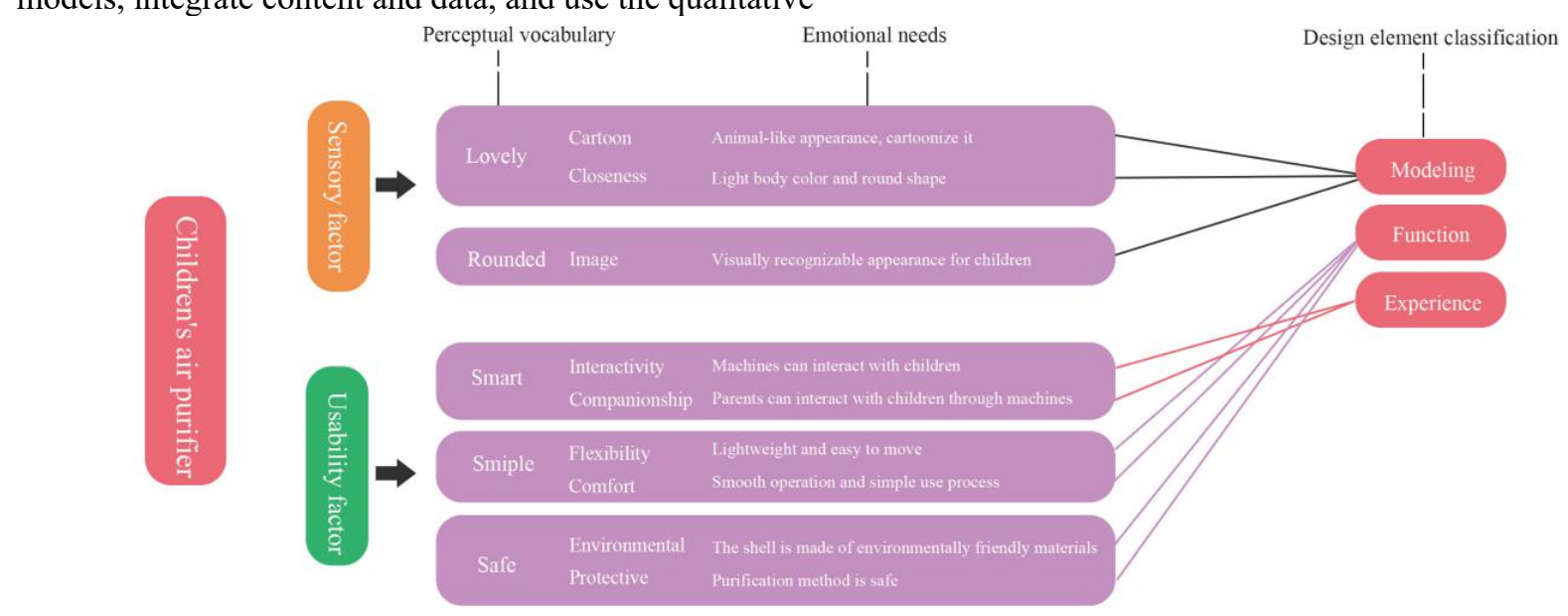

Figure 3. The hierarchical analysis diagram analysis method of perceptual engineering--- The hierarchical analysis method to obtain the three elements of children's air purifier design: shape, function, and experience. These three elements Later design examples will be guided. The specific analysis is shown in Figure 3.

\section{Examples of children's air purifier design}

\subsection{Design ideas}

Starting from the three aspects of the product's shape, function and experience, the emotional and innovative design of children's air purifiers was carried out. Focus on innovating the style and experience of children's air purifiers, and establish the emotional bond between parents and children through children's purifiers.

\subsection{Modeling aspects of children's air purifiers}

Based on the roundness and conciseness that are easily accepted by consumers in the results of factor analysis, combined with the interview results of children who like cartoon images, starting from the bionic design, the appearance characteristics of animals are refined. Combining product functions and human-computer interaction to unify form and function. The final rendering of the three-dimensional effect is shown in Figure 4.
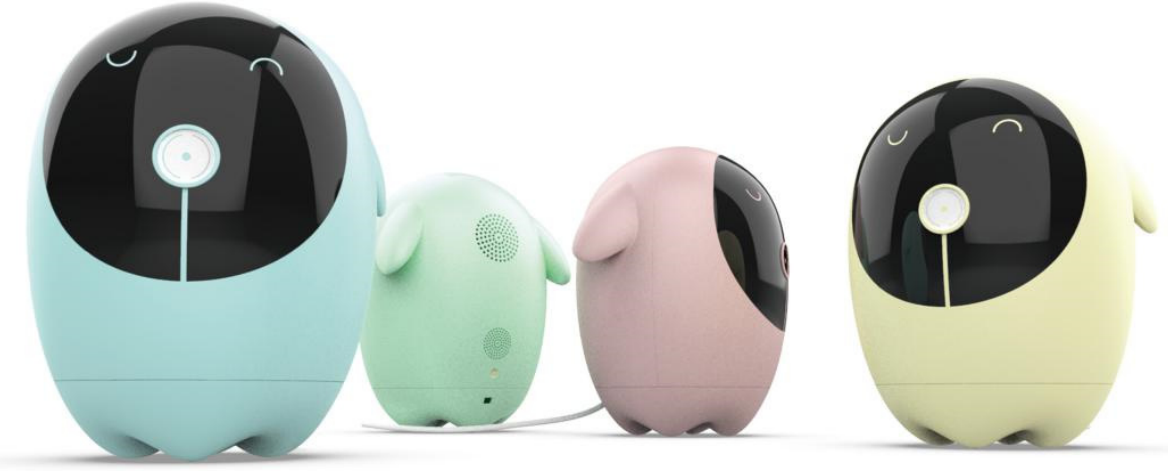

Figure4. 3D illustration of children's air purifier 


\subsection{Functional aspects of children's air purifiers}

In order to reflect the ease of use of children's air purifiers, there are three ways to turn on the machine. Through touch, voice wake-up and remote operation of the app, parents
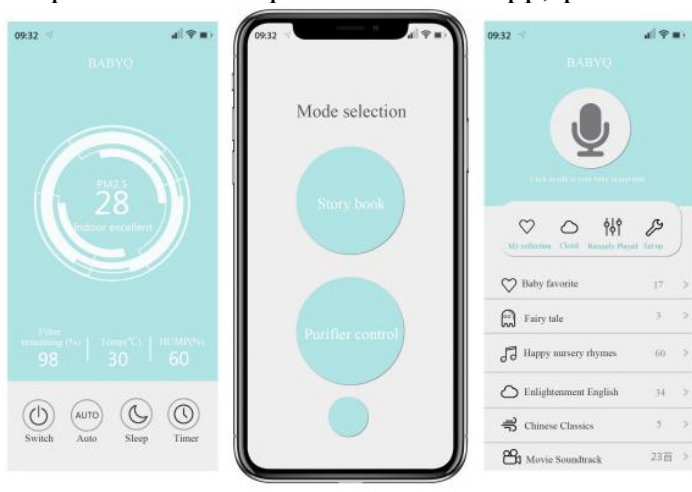

Figure5. Children air purifier function diagram

\subsection{Experience of children's air purifiers}

In order to reflect the companionship of parents, the purifier uses AI artificial intelligence voice interaction technology, built-in music and puzzle stories. The machine is connected to the parent's mobile phone through WiFi. When parents control the machine through intelligent voice, the machine will make corresponding answers and responses. This response will become more sensitive as the frequency of use increases, as shown in Figure

\section{Conclusion}

Using emotional design methods, the user demand model of children's air purifier is obtained, and the emotional bond between parents and children is established. It can be seen that integrating emotional elements into product design to extend product use is the core of emotional product design. The results of this study also has reference significance for the design of similar emotional products.

\section{References}

1. Hou Chang-chun, Feng Li-hong, Zhao Yan, et al. A prospective cohort study on the impact of indoor air quality on the incidence of acute upper respiratory infections in school-aged children $[\mathrm{J}]$. Public Health and Preventive Medicine , 2019, 30 (02): 9-13.

2. Tang Yun-feng. Design and implementation of intelligent system for air purifiers [D]. Southeast University, 2015.

3. Zhang Zong-deng, Tan Ru-jie. Application research of parent-child toys based on emotional design [J] .Packaging Engineering, 2019, 40 (08): 163-168.

4. Donald. A. Norman. Design Psychology $3[\mathrm{M}]$. Beijing: CITIC Press, 2nd Edition, June 2015. can flexibly choose the way to turn on the purifier in different use environments. In addition, in order to reflect the safety of children's air purifiers, the air purifiers use a highly safe negative ion purification method. As shown in Figure 5.
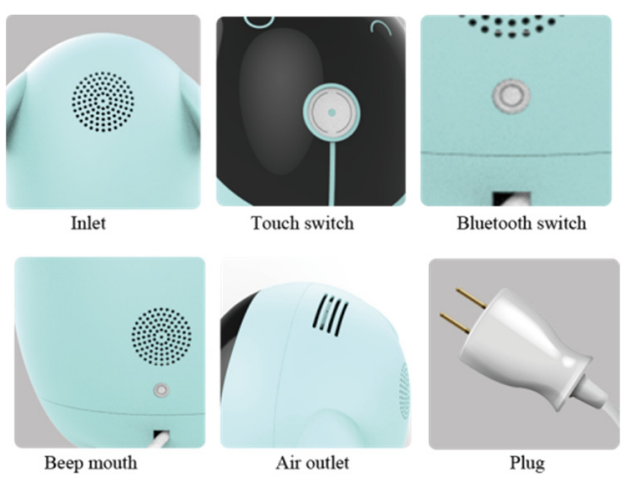

Figure6. Child air purifier interactive interface

5. Zhu Ji-hong, Yan Hai-yan, Liao Hai-jin. Construction of hierarchical model of emotional experience design for mobile Internet products [J]. Packaging Engineering, 2018, 39 (24): 177-182.

6. Su Jian-ning, Wang Rui-hong,Zhao Hui-juan, et al. Product shape optimization design based on perceptual imagee $[\mathrm{J}]$. Journal of Engineering Design, 2015, 22(01): 35-41.

7. Wang Nian-wen, Wang Jian. Research on modeling of home service robots for emotional needs [J]. Mechanical Design, 2018, 35(11): 111116.

8. Han Peng. Research on the design of emotionoriented children's scooter [J]. Mechanical Design, 2015, 32(11): 123-125. 